\title{
LIVEABLE AND HEALTHY CITY DESIGN
}

\author{
MARICHELA SEPE \\ IRISS National Research Council- DIARC University of Naples Federico II, Italy
}

\begin{abstract}
The relationship between health and urban design are complex because of the multiple elements, which play different roles in the city system. Indeed, urban happiness, liveability and health are concepts, which in the last years are become always more present in the urban planning studies. Although many theories agree on the benefits that people derive from factors such as green place, quality public space, safe place, social connectedness and clean air, it is not easy to assume and demonstrate that these improve liveability, happiness and then health. Many cities are playing their attractiveness and competitiveness on these elements and current indexes report the ranking of cities which are the most happy, liveable or healthy on the basis of factors in continuous change. In this way is difficult to understand what are the real reasons of success of certain places or cities and what to do to make a city liveable. Although it does not exist a unique recipe, it is possible to identify a mix of ingredients - with the right proportions - which is capable if not of guaranteeing at least strongly contributing to the creation and success of a healthy place. Starting from these premises, aim of this work is to illustrate the more recent theories on healthy and happy places and the original Ecoliv@ble+ design method, carried out in the framework of a CNR research project. The method aims at: identifying sustainable urban health, liveability and happiness from the user's point of view; identifying design interventions to enhance or create these factors. By way of example, the case study of Coal Harbour in Vancouver and relative observation complete the paper.
\end{abstract}

Keywords: liveability, urban health, urban happiness, public space, place identity, urban design.

\section{INTRODUCTION}

Urban health, liveability and happiness are concepts which in the last years are become always more present in the urban planning studies, with particular attention to urban design and public spaces [1]-[5]. Many societies rank the happiest city in the world or in a nation; many indicators try to report factors which are capable to report the liveability of a place; and topics related to healthy city are investigated in different manner, e.g. both in relation to the elderly or people with diseases, and with places which need to be improved from the pollution point of view.

These elements, indicators and factors are often referred to other concepts such as sustainability and resilience, which in turn are very used to define questions related to contemporary urban, social, place identity, environmental and economic topics [5]-[14].

If, from a part, the liveability and health concepts are always more explored in urban studies, on the other, due to the strong contamination coming from other disciplines, it is possible to understand why a place is liveable but is difficult to design a place being sure that this will be liveable and healthy.

According with recent studies on the fields, [15]-[17] some of the more recognized principles which make a place liveable include: good accessibility and orientation; presence of green; walkability; flexibility and variety of spaces; distinctivity; presence of facilities, events and activities; perception of safeness and security. And these factors are observable in the actions such as: happy people walking or cycling, children playing in parks, people of all age spending time in enjoying the place or making different activities.

Furthermore, as Sauders [15] asserts, air pollution, social connectedness, mental wellbeing, road danger, noise and physical activity can impact our health and it is important to implement good practice in urban design in order to introduce these elements into the 
planning at all scales. As many studies report, "urban planning and design can help to mitigate risk factors and to contribute to better mental health and happiness in the city". Factors such as "green place, active place, pro-social place and safe place (...) can facilitate innovative thinking (...) and promote better mental health and well-being" [16].

Indeed, as before mentioned, although theories agree on the benefits that people derive from these factors, it is not easy to assume and demonstrate that these improve liveability, happiness and then health. Starting from these premises, aim of this work is to illustrate the original Ecoliv@ble+ design method, carried out in the framework of the IRISS CNR research project "Contemporary urban landscape design: place identity, happiness, liveability, health and sustainability" (with the author's responsibility). The method aims at: identifying sustainable urban liveability and the factors which make places happy, liveable and healthy from the user's point of view; identifying design interventions to enhance or create both urban liveability and health. The emblematic case study of the Coal Harbour area of Vancouver complete the paper.

\section{URBAN HEALTH, LIVEABILITY AND HAPPINESS}

The relationship between health, liveability, happiness and urban design are complex because of the multiple elements which play different roles in the city system. Improving these factors with urban design, preserving place identity as well, is a great challenge.

With respect to the health theme - which is strongly connected with liveability and happiness - recent studies [16] report that firstly it is important to identify reasons why people who live in cities have greater risk to have health problems because of different factors. These include: disparities; crowding, noise, pollution, which can produce stress and encourage people in avoid social relationships that are important for mental well-being; low presence of green, possible reduction of leisure time, security and privacy.

Urban design and planning can contribute to decrease mental health problems and improve happiness in the city by reducing those risk factors. The Mind the Gaps frameworks created by McCay [16] identify four topics to make tangible the urban planner help, even though no one city still embodies all of them. The first is, as affirmed in different theories, access to urban green places, which can have many good factors including encourage exercise and social interaction; Wilson affirms that the good effect of green space stands in the fact that humans have biological need satisfied by the contact with other species; Ulrich states that the good effect is due to the contemporaneity of experience with aesthetics of nature and distance from everyday problems; the Kaplan (Rachel and Stephen) theory proposes that natural sites take the attention of people more than the non-natural because these last need contemporary concentration on many elements.

These theories can help to understand the positive effect of green space in mental health but are not enough to assume that the design of green space in a site can assure improvement in mental health. There are other factors which can influence negatively benefits in green space such as inaccessibility, bad management, a feeling of threatening that can discourage its use. Green spaces should be designed to be welcoming to different kinds of people and not monopolized by certain groups. Indeed, in some cases, green spaces can encourage behaviours, which are anti-social and discourage their use, because people feel unsafe in those spaces.

Successful green spaces should be walkable and have a suitable both physical and visual accessibility, which improve people's wellbeing. Accordingly, small presence of green in small space, streets or workplace is important as well.

Another important factor is to create different options of transport such as paths for pedestrians and bikes, which help to reduce sedentary habits. 
Furthermore, it is important to design public spaces with flexible use which are capable to create a sense of belonging and community, providing streets furniture for both resting and chatting and other elements which contribute to social activities and the general perception of wellbeing.

The perception of safety also contributes to a better quality of life and public spaces, and those that are capable to contribute to this feeling are successful. Some features, which can help this feeling, include suitable lighting and clear landmarks.

As Sauders [15] affirms people in the last decades are living longer than ever and so it is necessary to have healthier places to allow healthier life to all. This is because the daily activities such as work, travel and leisure are directly or indirectly connected to the place where these occur requiring suitable spaces. Elements such as air pollution, noise, road dangers and social connectedness can influence our health in different ways. The question is to understand what of these factors influence in a wider ways health and how to address them. Sauders suggests to address all of them at once and implementing good practice in urban design at the largest possible scale.

Indeed, places which are good for people are often healthy as well. In public realm, this often means the diminishing in motorised transport, which is used for carrying people who could instead walk or cycle. Motorised transport impacts in non-positive ways on air pollution and physical inactivity, transforming public spaces in noisy and unwelcoming areas. And these also increase the problems deriving by poor access and road danger, which are particularly important for the most disadvantaged people. Putting people at the centre of the urban design and decision potentially reduce the inequalities. Accordingly, Healthy streets, as Lucy Sauders suggests, identify 10 indicators, which indicate how design urban spaces and transport policies which make people first [15].

The most two important indicators - pedestrians from all walks of life and people choose to walk and cycle - have the aim to create places in which all people can participate in public life and both healthy and friendly environment design are considered in priority way.

The other eight indicators - People feel relaxed, Easy to cross, Clean air, not too noisy, Places to stop and rest, People feel safe, Things to see and do, Shade and shelter show clarify what is necessary to do to create inclusive, appealing and healthy places. Places, which do not have these characteristics, discourage people in using them. All professionals transport professionals, landscape architects, community groups, artists, planners and developers - are involved in the realization of Healthy streets and all the indicators are necessary for creating them.

A big challenge is to meet the demands of the different stakeholders in order to put in practice the principles, all often in limited spaces. Streets can be contested spaces and every street requires different approach according with social, physical, political or financial questions, which can weight in the general design not always in the same way. The important, as declared by Sauders, is that the general objective is to create public space which work better for people and are healthy and liveable for all.

Although the recognition of the importance of liveable public spaces for keeping people in good health, it is difficult to demonstrate that good urban design is capable to reduce for example hearth disease. The increasing in the number of people who spend time, walk and cycle on the streets can be shown easily and this is a first measure to demonstrate the success of the environment from the healthy point of view.

Furthermore, there exist important factors which create good interactions between places with behaviours, including: the promotion to daily activities such as walking or cycling which help people in having a healthy weight; the facilitation to easy access to healthy food; and the promotion of connected neighbourhoods and economic development. 
Finally, the Crappsley [17] approach to healthy design is mainly focused on streets and includes: reducing on-street parking and reallocating road space for vehicles, while adding space for walking and cycling; improving both the quality of footway zones and furniture and making easier for all age people to cross the streets; making bicycle infrastructures safer and more comfortable also introducing suitable separation with busy roads; slowing traffic, using different kinds of visual elements and tight corners; improving environmental elements, such as trees, sustainable drainage, shades streets and reduction of traffic noise; adding on-streets activities with both formal and informal activities which encourage people to use the space for social interaction or spend more time there; making safer the streets dissuading crimes and sense of insecurity, improving suitable lighting, natural surveillance; and making streets welcoming for all, improving accessibility.

Healthy and liveable urban design is capable to influence urban happiness in many ways, contributing to sustainability and the preservation of place identity.

\section{THE ECOLIV@BLE+ DESIGN METHOD}

The aforementioned considerations and the current studies in these topics [18]-[26] have led the author to create a method that, using a both rigid a flexible protocol, is capable to create healthy, liveable and happy places.

Ecoliv@ble+ design method aims to identify urban healthy, liveability and happiness and the factors which make places healthy, happy and liveable from the user's point of view. The part of analysis of the method - five phases - consists of different kinds of surveys, observations and questionnaires. The part of design is composed by three phases and includes the check of consistency with the 25 principles of the Charter of urban health, liveable and happy urban design.

Phase 1 of the method consists in the definition of the study area; it needs to go on the site in question and decide, through an inspection, whether to confirm the delimitation decided beforehand or modify it.

Phase 2 is characterized by the observation of the characteristics of the place through three surveys concerning the kinds of activities, the perceptions, and the elements that contribute to the perception of urban healthy, happiness and liveability.

In the survey 1, the types of people - locals, visitors, professionals - and activities enjoyment, passing by, work - are observed. It needs to observe these activities from the quantitative point of view, in order to collect data concerning in what percentage the activities are present in that place and how influence its liveability and healthy. Then, it needs both measure and observe the presence of persons from the quantitative point of view. Accordingly, the frequency with which the activities are repeated or implemented and with what pace is measured: namely, it is observed if that activity is carried out with a rapid, slow or moderate pace.

The survey 2 consists in the identification of singular and mixed perceptions. The singular perception includes the visual, auditory, tactile, olfactory, taste perceptions, while the mixed ones include chaos, serenity, disorder, joy, harmony, disorientation, un-comfortability and so on, deriving from the sum of one or more perceptions. Their quantity is expressed as light, medium and high amount percentage; the quality is expressed as pleasant, non-influential and annoying perceived perception.

The survey 3 of this phase consists in the observation of the elements which contribute to the health and happiness sensation such as constructed and natural elements, suitable pedestrian areas, transportation modes, good quality equipment and services (furniture, pavement, wireless, etc.). 
Finally, from the intersection of these data, a first result on the degree of healthy, happiness and liveability are obtained, resulted from the surveys on the place in object.

Phase 3 consists in a questionnaire to the people who use the sites aimed at identifying factors and elements which give them the sensation of healthy, happy and liveable place.

Questions may include the following and will be modified in accordance with the place characteristics.

1. This place gives you a feeling of happiness or sadness/ liveability or discomfort/ health or unhealthy?

2. What are the elements that give you the above sensations?

3. What are the main facilities that give in your opinion quality to this place?

4. What are the activities that you act in this place and how often?

5. What do you think about the presence of many or few people here? Do you think that it is capable to improve the pleasantness or unpleasantness of the place?

6. According to the current place healthy, liveability and happiness what could be done in order to improve this place?

7. What is a healthy/happy/liveable place that you remember in this city or elsewhere?

8. How - in your opinion - the weather conditions might influence the perception of liveability or happiness this place?

Phase 4 is that of the analysis of the traditional cartography in order to understand the elements that compose the place in terms of the type of the historical and architectural elements, urban fabric, the natural environment (green areas, sea, hills, etc .), and other public spaces in the surrounding area. A collection of projects of urban design in development on these areas can complete this analysis.

Phase 5 involves the construction of the map of urban healthy, liveability and happiness with the identification of spaces and features that give to the people who use that place the perception of these factors.

The map will be the result of the different survey operations, analysis and observation, which were collected on the sites in object.

In phase 6 - the most important for the design - the check of the current degree of healthy, liveability and happiness is carried out. This is obtained through the study of both intrinsic and extrinsic factors contained in the map which are capable to determine urban healthy, liveability and happiness. The intrinsic factors include the perceptions, tradition and culture. Extrinsic factors include the architecture, facilities and urban furniture. The aim is that of identifying a map of those areas where there is a minor presence of healthy, liveability and happiness, which are underused with respect to the place in general and where the project interventions have to be concentrated. These areas could be represented by both perceived empty spaces or physical empty spaces - such as a non-utilized square, or an area destroyed following an environmental disaster. Furthermore, these areas can be marginal with respect to the place or central or can also be constituted by the whole study place. The check is carried out through the 25 principles of urban health, liveable and happy design concerning the aforementioned Charter.

1. A healthy, liveable and happy place is a space that can transmit feelings of healthy, liveability and happiness to everyone who uses it. 
Table 1: Ecoliv@ble+ design method.

\begin{tabular}{|c|c|c|c|}
\hline Phase & Objective & Actions & Product \\
\hline 1 & Definition of the area & Visits on site & Map with the definition of the borders \\
\hline 2 & $\begin{array}{l}\text { Observation of } \\
\text { characteristics of the place }\end{array}$ & $\begin{array}{l}\text { Surveys of } \\
\text { People } \\
\text { Activities } \\
\text { Perceptions } \\
\text { (singular and } \\
\text { mixed) } \\
\text { Elements } \\
\end{array}$ & Map of characteristics of the place \\
\hline 3 & Questionnaire to place users & $\begin{array}{l}\text { Identification of } \\
\text { elements which } \\
\text { make that place } \\
\text { healthy, liveable } \\
\text { and happy from } \\
\text { people point of } \\
\text { view }\end{array}$ & Mosaic of user's ideas \\
\hline 4 & Analysis of cartography & $\begin{array}{l}\text { Identification of } \\
\text { elements that } \\
\text { compose the place }\end{array}$ & $\begin{array}{l}\text { Map of the traditional elements which } \\
\text { compose the place }\end{array}$ \\
\hline 5 & $\begin{array}{l}\text { Identification of factors of } \\
\text { urban healthy, liveability } \\
\text { and happiness }\end{array}$ & $\begin{array}{l}\text { Overlapping of all } \\
\text { data collected }\end{array}$ & $\begin{array}{l}\text { Map of urban healthy, liveability and } \\
\text { happiness }\end{array}$ \\
\hline 6 & $\begin{array}{l}\text { Check of the degree of } \\
\text { healthy, liveability and } \\
\text { happiness }\end{array}$ & $\begin{array}{l}\text { Overlapping } \\
\text { between the map } \\
\text { of urban healthy, } \\
\text { liveability and } \\
\text { happiness and the } \\
25 \text { principles of } \\
\text { the Charter of } \\
\text { UHLH }\end{array}$ & Map of the areas to be improved \\
\hline 7 & $\begin{array}{l}\text { Check of the design ideas } \\
\text { with the users of the place }\end{array}$ & $\begin{array}{l}\text { On-site } \\
\text { questionnaire and } \\
\text { research on the } \\
\text { websites with the } \\
\text { user requests }\end{array}$ & $\begin{array}{l}\text { Mosaic of degree of pleasure on the } \\
\text { design ideas }\end{array}$ \\
\hline 8 & $\begin{array}{l}\text { Identification of project } \\
\text { interventions for the } \\
\text { realization of the Charter } \\
\text { principles }\end{array}$ & $\begin{array}{l}\text { Overlapping of all } \\
\text { data collected }\end{array}$ & $\begin{array}{l}\text { Map of urban health, liveability and } \\
\text { happiness design }\end{array}$ \\
\hline
\end{tabular}

Accordingly, it is important:

2. To encourage the use of the place by people of different age groups, from children to the elderly.

3. To eliminate architectural barriers, which might discourage people from frequenting that space.

4. To create a suitable balance between the elements of nature, landscape and equipment in the composition elements of the space.

5. To have both in streets and public spaces natural lighting during the day and artificial at other times, avoiding artificial light in daily hours.

6 . To retain an adequate state of cleanliness and maintenance.

7. To create suitable spaces for dogs and domestic animals, which are accompanied by their owners. 
8. To create a sense of security and safety to those who walk, cross, rest, and do different activities in the public spaces.

9. To minimise or eliminate the noise generated by public transport.

10. To improve suitable pedestrian and cycle lines.

11. To fully perceive naturally occurring smells - e.g. wood, grass, sea, etc.

12. To have direct contact with natural materials, preferably local, used in the design of the space.

13. To have the presence of water in different shapes (e.g. fountains) which promotes the vitality of the place.

14. To have the possibility of doing actions - such as walking, watching, etc. - with a moderate or slow pace, promoting opportunities to take breaks in the space.

15. To have the possibility of using the space in different weather conditions and seasons, contributing at the same time to its continuous good state of maintenance.

16. To preserve both the place identity and the intangible characteristics of the site and its surroundings.

17. To both allow and promote different types of functions such as games, breaks, walking, etc.

18. To facilitate gymnastic activities - also slow ones - with the presence of small equipment or a designated space.

19. To have the possibility of doing actions that normally are not permitted - such as walking barefoot in the water or in designated public areas - improving a feeling of freedom and joy.

20. To encourage the presence of art in its different forms.

21. To promote sculptures, games, or other elements and amenities which can bring a smile to a person's face, promoting a state of liveability and happiness.

22. To promote participation, namely the feeling of being able to contribute to the life of that place, increasing the sense of belonging.

23. To encourage the consideration of the place as symbolic of the neighbourhood, improving the perception of its identity.

24. To promote the educational function, which a place has - e.g. clearly displayed information about history of the place etc. or suitable ways to use it - increasing its intrinsic value.

25. To facilitate the use of new technologies to increase the knowledge of its intangible values and history, offering a more profound experience of the place.

Phase 7 concerns the check of the emerged first design ideas - with the users of the place to obtain a mosaic of degree of pleasure on these. Two typologies of questionnaires are carried out: the questionnaire on site that has to be administered to the different kinds of users and visitors of the place; the research on the web-sites with the user requests. In the first kind of questionnaire, the design hypothesis is verified with demands selected by who carried out the study, ad hoc with respect both to the place and the results of the phase 7 .

The second kind of questionnaire is constituted by or the study of web reviews concerning booking of tourist services (e.g. booking or trip advisor) already on-line or ad hoc new tools, such as the realization of blogs or other social network tools to support this and other phases of the project.

Answers to the different questionnaires administered on site and online will be overlapped, constituting the participative part of the project, but also the possibility of comprehension of the place in a wider manner.

Following the check of consistency with the Charter of phase 6 and the results of the phase 7 questionnaires, the identification of project interventions is carried out. In phase 8 - the last 
one - the design of the project interventions in the areas in object is carried out trough: the overlapping of the results of the previous phases; a check of consistence with spaces and urban furniture and equipment already present; the identification of the use of the traces urban, cultural, etc., already existing in the place.

The existing traces to which connect the project interventions are not only the urban ones, but also the cultural and natural ones belonging to memories, perceptions and other tangible and intangible factors. A detailed analysis will provide the more suitable information in order to make emerge the existent characteristics and peculiarities and connect the project of new parts. In this way a map of urban health, liveability and happiness design will be obtained. The design of the new spaces to be harmonized with the existent ones is an important point, above all when the final objective is constituted by the urban health, happiness and liveable achievements, concepts which are often hardly reachable.

\section{THE CASE STUDY}

The case study which will be illustrating in synthesis in the following is constituted by the new Coal Harbour area in Vancouver.

Vancouver is a city in the British Columbia province of Canada. It has a particular landscape given by mountains from a side and sea, all surrounded by a good balance between natural and built environment. During the 1970 and 80s [27], Vancouver was interested by a out migration of the middle classes from inner city to the suburbs. The result was an economic stagnation which finished with the urban regeneration investments for the 1986 World exposition. The development revitalized the downtown into a mixed-use area that helped to obtain a wider regeneration of the rest of the city.

Many new policies were utilized for the new vision of the historical centre contained in the Living First Strategy. This is focused on the improvement of the quality of life, walkability, public transport, local services and quality public spaces. In addition, other tree factors have been introduced in order to regulate the planning of Vancouver, namely: "the promotion of tall buildings in key city centre locations, the preservation of important views to water bodies and mountain's encircling the city, and the promotion of the development of buildings with setbacks stepping down to the harbour and False Creek". These policies - all related to both the height limitation of tall buildings and the protection of the view corridorsinclude: The downtown official development plan (1975), The special review processes (2002) of the higher building advisory panel, The downtown capacity and view corridor study (2008), The historic area height review (2011) and the higher building review, The View Protection Guidelines (2011); and the General Policy for Higher Buildings (2014).

In Vancouver, the City Council is independent from the provincial legislature. For this reason, it can decide to realize a specific scheme concerning for example additional height or density although against the planning rules, if the benefits capacity is demonstrated. The accepted new design of view will result in a re-zoning of the interested area and corridors.

This system brings benefit to different subject such as the city, the local community, and the developers of the project. Each change is carried out with the idea to conserve and protect heritage and natural environment [27].

The area which was chosen for the study - Coal Harbour - is particularly emblematic for the topics of the paper. It contains many elements of interest including the presence of public spaces, the sea, mixed use and many activities for free time.

The decision to analyse it stands in the fact that this is a new area of urban, socio and environmental regeneration in which the City of Vancouver is investing many energies to improve both its liveability and competitiveness. 
According with the first phase of the Ecolivable+ design method, the on-site visits confirm the Coal Harbour area in its whole as the place of analysis. In particular, Coal Harbour starts at Canada Place to the east and ends at the beginning of Stanley Park to the west; it is bordered to the north by Burrard Inlet and by West Georgia Street to the south. Coal harbour is a pedestrian area. Observations were carried out both during the weekly and we. days; the data which were collected are synthetized in the following.

The activities (phase 2 of the method) include walking, cycling, resting, watching the panorama, eating, making a flight touristic tour, and taking photos and selfies, all done with high frequency by the people who use this place (Figs 1-2).

Each activity has its own space, e.g. there is a line for pedestrians, one for cyclists and skateboarder in both directions, suitable grass with benches to take a break, and so on.

Furthermore, there are artistic sculpture of different types - including the Canada "Drop", a steel sculpture of $20 \mathrm{~m}$ heights, a sort of homage to the power of nature which represents a kind of landmark of the place and the aluminium LightShed - and a little garden with images of the Coal Harbour and Vancouver history.

The places are of very good quality and materials and the spaces devoted to all the activities are suitable, giving the general perception of a healthy, liveable and happy place. And, not last, this area gives a perception of safety. The only element which is in some moments annoying is constituted by the noise of the helicopter engines which are used for the touristic tours.

Pleasant perceptions are in particular visual, smell and touch due to the beautiful views on both the harbour and the mountains, the presence of grass with trees and flowers, the well maintained and comfortable floor.
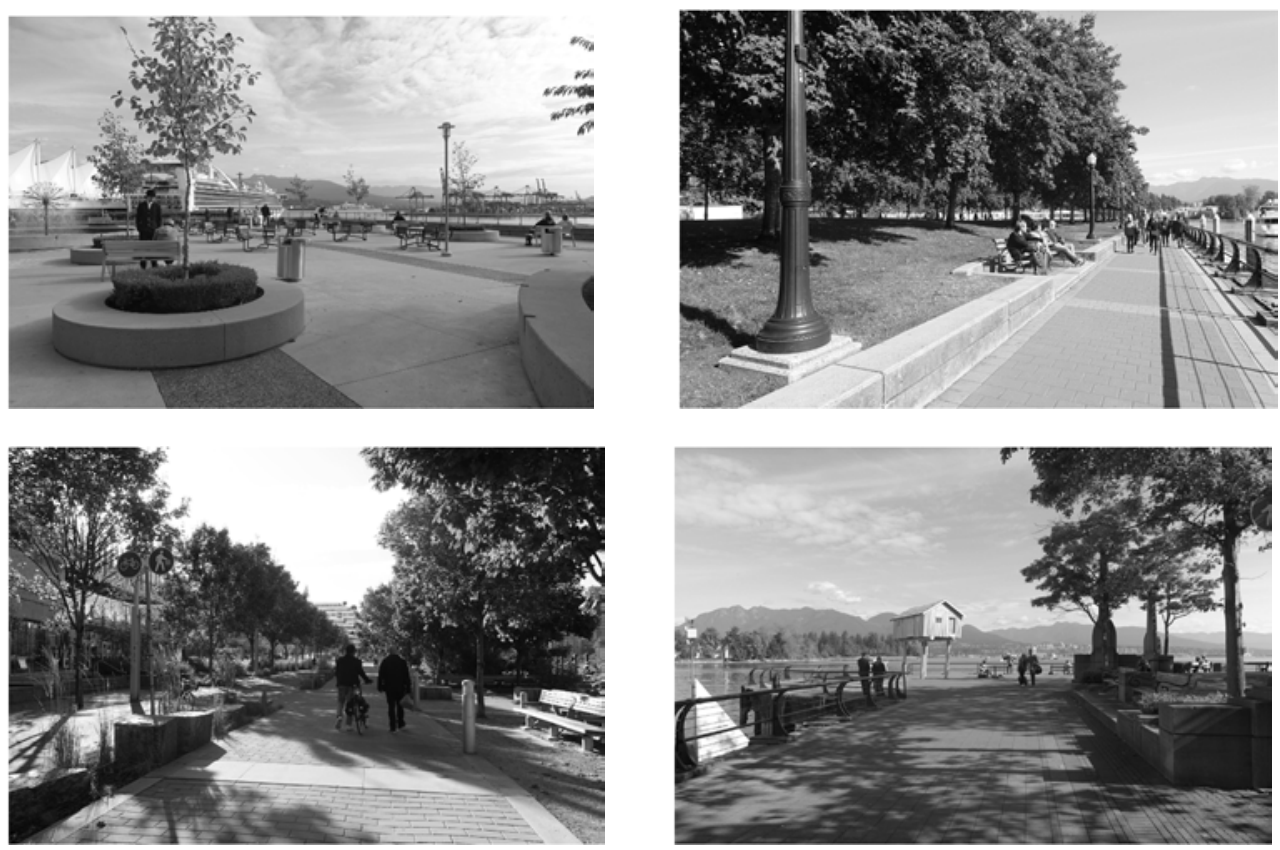

Figure 1: Coal Harbour, Vancouver, images of the area. (Source: Photos by the Author.) 


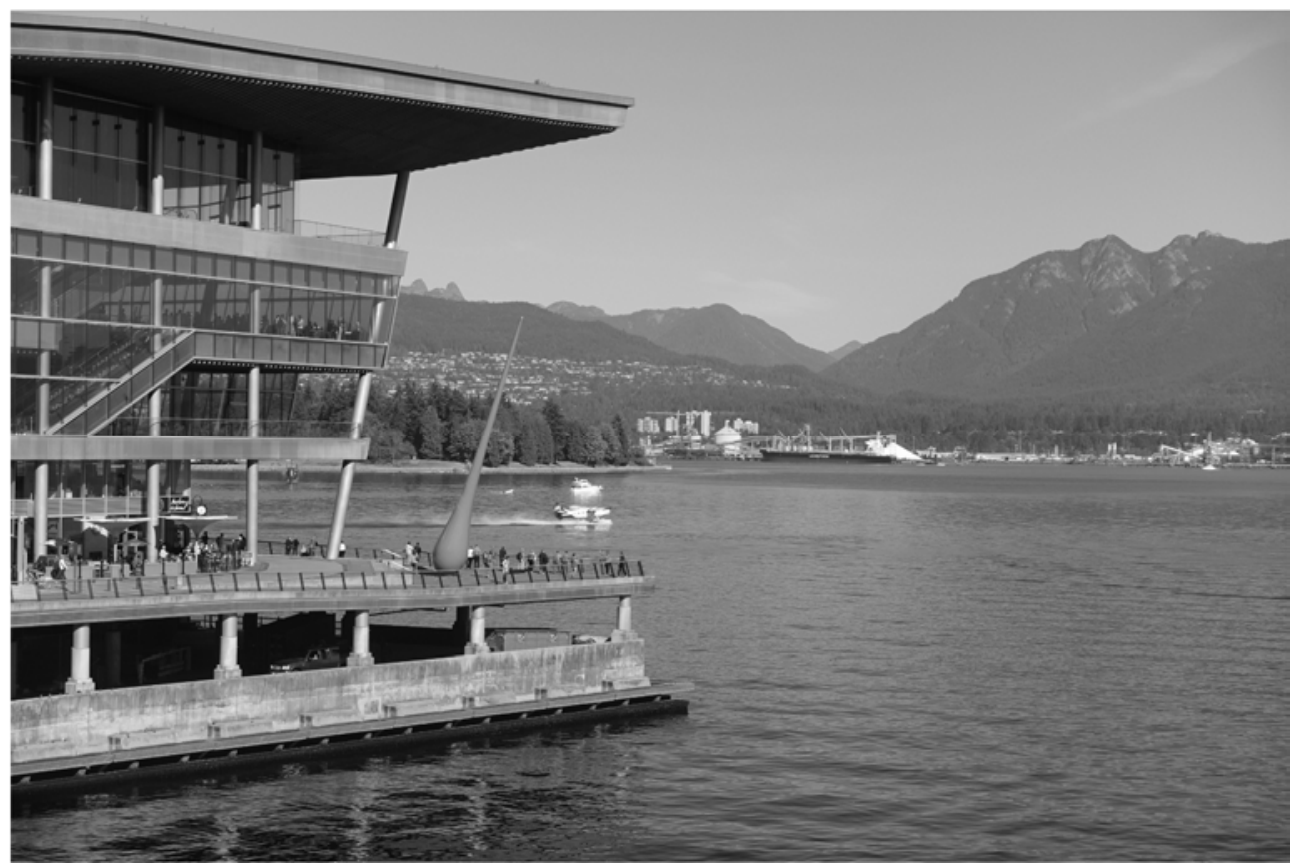

Figure 2: Coal Harbour, Vancouver, view with the high blue sculpture, the seaplane and the Convention centre. (Source: photo by the Author.)

People are constituted by professionals of many kinds (here there are many offices, hotels, a harbour and a huge Congress centre), inhabitants and visitors from all over the world.

Answers (phase 3 ) by respondents - about 100 administered to users of place from all over the world - were quite similar with respect to the perception of happiness, liveability and health given by this place.

Different were the answers concerning the question "What is a healthy/happy/liveable place that you remember in this city or elsewhere".

Some tourists answered, "Stanley Park", others "East False Creek" and still others Granville, all in Vancouver. Inhabitants add other Vancouver places including "False Creek South" and Yaletown. With respect to the question "What are the main facilities that give quality to this place?" the majority of respondents answered the good mix between beautiful environment, art, quality streets furniture, restaurants and bar.

The different functions which are present in the area offer are used with high frequency by people of different age, provenience and professions.

The main factors which are reported in the phase 5 of the method - the map of urban health, liveability and happiness - are constituted by: the suitable balance among a beautiful natural environment - visible from the whole area - the variety of activities which can be done - both free and with fee - the good quality of street furniture - well maintained and managed - the presence of art - above sculptures - which give a good and harmonic mix of new and old - and safety perception - also demonstrated by the fact that people of different age and motorial abilities use this area during all the day hours. 
By checking the consistence between the results of different surveys and the Charter of 25 principles, in this case urban health, liveability and happiness were observed. In Coal harbour - for this reason - the phases of design were not necessary

\section{OBSERVATION AND CONCLUSION}

The Ecolivable+ design method, carried out in the framework of the IRISS CNR research project "Contemporary urban landscape design: place identity, happiness, liveability, health and sustainability" (with the author' s responsibility), which was presented in this paper is an evolution of both the original PlaceMaker [6] - which was devoted to the identification of elements which constitutes the place identity and intervention for its enhancements - and Ecolivable design method [2] which was devoted to identification and design to the factors capable to give happiness to the people who use the places.

Following the results of the different case studies carried out to test the methods and according with the more actual needs of people and society, the new method - in which the "+" was added - has been enriched by the author - with two important factors, namely health and liveability.

Identity of places has constituted by very tangible elements such as the architecture of buildings, the urban morphology, etc. Urban happiness can be given by both the perceptions and intangible aspects and is strongly connected to architectures, public spaces and natural environment, although with a certain degree of subjectivity. Health is meant as factor important not only to resolve diseases but to improve well-being, which can be supported by a suitable way to design places and public spaces, as illustrated in the theoretical section of the paper. Liveability is a factor that is also important in urban design and is related to a more general perception of beauty, quality and comfort of the place, not necessarily in connection with the health. Indeed, urban health, liveability and happiness are three concepts that are strongly interwoven and are related to the sustainability and well-being of both people and place. To identify the presence of these three factors in a site and realize an urban project which contain these is - as before mentioned - a great challenge.

The Ecolivable case studies that have been carried out concern different kinds of spaces, with different functions and use, but which are substantially public and are particularly representative of the city of belonging. These include: squares - Stadtlounge in St Gallen, Place des Voges in Paris, Piazza del Campo in Siena and Piazza Trevi in Rome - urban parks - Millennium Park in Chicago, City garden in Saint Louis (Missouri), and Promenade du Paillon in Nice; waterfronts - Hankou River in Wuhan, Lungomare Caracciolo in Naples, Bordeaux Waterfront in Bordeaux, The Bund in Shanghai, Coal Harbour in Vancouver and HafenCity in Hamburg - pedestrian and semi-pedestrian thoroughfares - the Ramblas in Barcelona and the Graben in Vienna - and cultural districts - 798 Art District in Beijing, Nanluoguxiang in Beijing, and Museums Quartier in Vienna.

The experiments concern public spaces, which are well known and successful, in order to comprehend behaviours and movements of people, and physical elements which contribute to urban healthy, liveability and happiness. This is carried out through a protocol with different kind of surveys; among these, there is the survey realized using ad hoc schedules. As regards, the schedules, can be further improved to better collect data concerning movements of people which are hardly predictable before the direct observation, different for any place and part of it.

Another focal point is the identification of the intrinsic and extrinsic elements, which contribute to the urban liveability, health and happiness. Indeed, those elements are in strong relation each other and, consequently, the identification of the areas which need to be improved from those points of views is complex. 
Another important aspect is the integration between the answers to the questionnaires both of analysis and design -administered on site and those collected from internet web sites. The typologies of both answers and questions, and people who participate in these, could be very different making difficult to have a univocal result.

The results of the case studies enabled the creation of the Charter of urban health, liveable and happy urban design with twenty-five principles, which is part of the method. The 25 principles aim to provide a checklist, which the project has to satisfy in order to enhance the three factors - health, liveability and happiness - of the place in question. The principles should be considered as dynamic, in keeping with the increasingly rapid rates of change in a place, which lead to continually expanding concepts of health, liveability and happiness.

Accordingly, it needs to take into account that design hypothesis which are reached following the method are - given some necessary elements - only one of the possible solutions. From Ecolivable + design method many and different design ideas can derive.

The case of Vancouver has been particularly emblematic because of the strong energies which the city is using to reach healthy and liveable place for all. The area of Coal Harbour, in particular, has characteristics and facilities which make it a comfortable place, which encourage its use for the many activities which it offers, including the taking a break. The particularly beautiful environment - composed by both sea and mountains - give to people the possibilities of doing many things, many times and for long time, creating a satisfying experience which can be daily repeated. Furthermore, the perception of a safe place plays an important role for its health, liveability and happiness. Finally, the surveys and questionnaire demonstrate how a good urban design can be well perceived by people - both inhabitants and tourists - of different age, culture and habits and contribute to its success in terms of socialization, liveability and sustainability.

\section{REFERENCES}

[1] Carmona, M., Heath, T., Oc, T. \& Tiesdell, S., Public places-Urban spaces, Architectural Press: Oxford, 2010.

[2] Sepe, M., The role of public space to achieve urban happiness. International Journal of Sustainable Development and Planning, 2(4), pp. 724-733, 2017.

[3] Friedmann, J. \& Douglass, M., Cities for Citizens: Planning and the Rise of Civil Society in a Global Age, Chichester, NY: John Wiley \& Sons, 1998.

[4] Porteous, J.D., Environmental and Behavior: Planning and Everyday Urban Life, Addison-Wesley: Reading, Massachusetts, 1977.

[5] Project for Public Spaces, How to Turn a Place Around: A Handbook for Creating Successful Public Spaces, Project for Public Places: New York City, NY, 2001.

[6] Sepe, M., Planning and Place in the City, Mapping Place Identity, Routlege: LondonNew York, 2013.

[7] Lynch, K., The Image of the City, MIT Press: Cambridge, 1960.

[8] Appleyard, D., Liveable Streets, University of California Press: Berkeley, 1981.

[9] Montgomery, J., Making a city: urbanity, vitality and urban design. Journal of Urban Design, 3, pp. 93-116, 1998.

[10] Friedmann, J., Place and place-making in cities: a global perspective. Planning Theory \& Practice, 11(2), pp. 149-165, 2010.

[11] Gehl J., Cities for People, Island Press: Washington, 2010.

[12] Sepe, M., Preserving, reconstructing and enhancing the place identity: identifying principles of urban sustainability with placemaker method. International Journal of Sustainable Development and Planning, 9(2), pp. 277-300, 2014. 
[13] Zelinka A. \& Brennan D., Safescape, Creating Safer, More Livable Communities Though Planning and Design, Planner Press APA: Chicago, 2001.

[14] Florida R., Mellander C. \& Rentfrow P.J., The happiness of cities. Regional Studies, 47, 613-627, 2013.

[15] Saunders, L., Healthy cities. Urban Design Group Journal, 142, pp. 12-39, 2017.

[16] McCay, L., Designing mental health into cities. Urban Design Group Journal, 142, pp. 25-27, 2017.

[17] Crappsley, R., Designing streets for good health: now and in the future. Urban Design Group Journal, 143, pp.10-11, 2017.

[18] Taylor, A.F., Kuo, F.E. \& Sullivan. W.C., Growing up in the inner city: Green spaces as places to grow. Environmental Behavior, 30(1), pp. 3-27, 1998.

[19] Zidansek, A., Sustainable development and happiness in nations. Energy, 32, pp. 891897, 2007.

[20] Montgomery, C., Happy City, Penguin, London, 2013.

[21] Burns, G. W., Naturally happy, naturally healthy: The role of natural environment in well-being. In F. A. Huppert, N. Baylis, and B. Keverne eds. The Science of Wellbeing, Oxford University Press: New York, 2005.

[22] Ballas, D., What makes a "happy city"? Cities 32, pp. 539-550, 2013.

[23] Burns, G.W., Naturally happy, naturally healthy: The role of natural environment in well-being. In Huppert, F.A., Baylis, N. \& Keverne, B. eds., The Science of Well-being. New York: Oxford University Press, 2005.

[24] Burton, L. Mental well-being. In H. Barton, S. Thompson, S. Burgess \& M. Grant (eds) The Routledge Handbook for Health and Well-being, London: Routledge, 2015.

[25] Kyttä, M. et al., Urban happiness: context-sensitive study of the social sustainability of urban settings. Environment and Planning B, 43(1), pp. 34-57, 2015.

[26] Sepe, M., Improving sustainable enhancement of cultural heritage: smart placemaking for experiential paths in Pompeii. International Journal of Sustainable Development and Planning, 10(5), pp. 713-733, 2015.

[27] Mathewson, D. \& Karaga, K., Vancouver as a benchmark. Urban Design Group Journal, 145, pp. 25-27, 2018. 